\title{
Falls and Physical Performance among Frail Sexagenarians and Septuagenarians
}

\author{
Ganesan Kathiresan, Sandra Devie, Sunnelly Velintina, Stellah Lenson, Nur Idawanny, Nur Asyikin, \\ Nurul Hijah
}

Department of Physiotherapy, School of Allied Sciences, Masterskill University College, Sabah, Malaysia.

Email: gans_therapist@yahoo.co.in, kathiresan@masterskill.edu.my

Received August $9^{\text {th }}, 2010$; revised August 10 $0^{\text {th }}, 2010$; accepted August $12^{\text {th }}, 2010$.

\begin{abstract}
Background: In Malaysia, there are few population-based studies on the factors associated with falls, and there is a lack of prevention of falls among older adults in primary and secondary health care, particularly in terms of physical activity that could improve the physical performance of individuals at risk of falling. Therefore, the objective of the present study was to determine the relationship between physical performance, the number of falls and the sociodemographic, physical, clinical and functional characteristics of older adult fallers. Methods: Cross-sectional study carried out among 72 older adults with a history of falls in the past year, $65.3 \%$ of which were women. The participants received care at the geriatric outpatient clinic and divided into the following groups: worst physical performance (WPP) and best physical performance $(B P P)$, one-time fallers $(1 F)$ and frequent fallers $(2 F)$. Sociodemographic, clinical, physical and functional characteristics were considered as independent variables. Comparison analysis between the groups was conducted. Results: The WPP group was older and had a higher number of illnesses and less independence in most motor dimension tasks compared to the BPP group. The $2 F$ group had a higher number of illnesses, less handgrip strength and less independence in the bowel management task in the motor dimension of the Functional Independence Measure (FIM) compared to the $1 F$ group. Conclusions: Among older adults fallers, poor physical performance is associated with more advanced age, more illnesses and less functional independence. Moreover, recurrent falls are associated with more illnesses, less muscle strength and less functional independence in the bowel management task.
\end{abstract}

Keywords: Aging, Exercise, Fall, Gait

\section{Introduction}

Falls in older adults lead to consequences related not only to social aspects, but also to economic, physical and psychological aspects of the individual's life [1]. The incidence of falls in individuals over 60 years of age stands out due to the fact that the consequences of a fall can be complex and lead older adults to conditions of morbidity, mortality and dependence in the activities of daily living (ADLs) [2-4]. Falls are a significant cause of morbidity and mortality among the elderly [5].

According to the literature, changes in the mobility of older adults result from environmental factors, physiological modifications associated with the aging process, or even from the consequences of the lifestyle adopted by the individual throughout his life [6-8]. The decline in physical capacity is related to the reduction in muscle strength, to impairments in gait performance and to changes in static balance $[9,10]$. These parameters can vary according to the individual's socio demographic, physical and functional characteristics, and they are linked to falls because falling can result from the body instability caused by this decline.

Older adults often seek outpatient care to treat these consequences that affect the functionality and quality of life of this age group. Studies of this nature are important because they describe the profile of the older adults that are at greater risk of falling, which can prevent the occurrence of this event, maintain a standard of quality of life for older adults and reduce costs to the country's public health systems $[11,12]$.

In Malaysia, there are few population-based studies on the factors associated with falls, and there is a lack of prevention of falls among older adults in primary and secondary health care [13], particularly in terms of physical activity that could improve the physical performance of individuals at risk of falling. Therefore, the objective of the present study is to determine whether there is a relationship between physical performance, the number of falls and the socio demographic, physical, clinical and 
functional characteristics of older adult fallers.

\section{Materials and Methods}

This is a cross-sectional study, in which the sample was composed of male and female Sexagenarians (60 to 69 years) and Septuagenarians (70 to 79 years) from the Kota kinabalu, East Malaysia area, who received care at the Geriatric Outpatient Clinic.

As many older adults as possible were approached each day to inquire about their willingness to take part in the study, their availability for an interview and their compatibility with the inclusion criteria. Data were collected through an individual interview, with or without the presence of the caregiver. Each interview lasted from one hour to one and a half hours. Of the 145 older adults interviewed, 72 had a history of falls and were selected to join the present study which aimed to describe the characteristics of fallers only.

\subsection{Exclusion Criteria}

If they had not fallen in the past year, refused to participate, received care on a Stretcher, had cognitive impairment identified by the Mini-Mental State Examination [14] or had a diagnosis that would impair the comprehension of the questionnaires of the study's protocol or impair the performance of the tasks contained in this protocol.

\subsection{Outcome Measures}

The following instruments were used for data collection.

- First, the socio demographic characteristics were obtained, including sex, age group and literacy.

- Second, the clinical characteristics were recorded, including the occurrence of falls (number, fractures, hospitalizations), according to the Kellogg International Work Group (KIWG) on the Prevention of Falls by the Elderly [15]. The older adults and/or their caregiver were asked about the incidence of a fall in the past year and about the number of associated diseases, medications in use, and visual capacity determined by the measure of visual acuity using the Snellen chart. Visual acuity $\geq 20 / 60$ in the best eye, with corrective lenses, if used, was considered low vision.

- Third, the physical characteristics were obtained for regular physical activity, levels of physical performance through the Short Physical Performance Battery (SPPB) in the domains balance, gait, and lower limb (LL) strength [16], and handgrip strength (HS) measured with Hand held dynamometer.

- Finally, functional characteristics were assessed through the Functional Independence Measure (FIM) [17, $18]$.

For the comparison analysis of the present study, we considered the criterion variables of physical perform- ance level (gait, balance and LL muscle strength) and number of falls as outcome. The groups were divided into $1 \mathrm{~F}$ (one-time fallers) and $2 \mathrm{~F}$ (frequent fallers in the past year), and they were also divided into worst physical performance (WPP) for scores 0-6 in the SPPB and best physical performance (BPP) for scores 7-12 in the SPPB. The median was 6.0; therefore the WPP group was defined as those who scored from 1 to 6 , and the BPP from 7 to 12 .

The statistical analyses were descriptive and comparative by means of chi-square tests (categorical data), Student's $t$ test (parametric, ordinal or interval data) and Mann-Whitney (non-parametric, ordinal and interval), considering the results of the data normality test (Kolmogorov-Smirnov). The significance value was set at $\mathrm{p}<$ 0.05 .

\section{Results}

Most of the older adults were female (65.3\%), Septuagenarians $(58.3 \%)$, with an incidence of two or more falls $(56.2 \%)$ in the past year and without low vision $(63.9 \%$; Table 1).

With regard to functional independence, the older adults had high mean scores in each of the FIM motor tasks, and more than a half of the participants reported complete independence in these tasks, except in the items of dressing the lower body, bladder management, walking

Table 1. Description of socio demographic and clinical variables of older adults $(n=72)$

\begin{tabular}{|c|c|}
\hline Variables & $\mathbf{N}(\%)$ \\
\hline \multicolumn{2}{|l|}{ Sex } \\
\hline Male & $25(34.7 \%)$ \\
\hline Female & $47(65.3 \%)$ \\
\hline \multicolumn{2}{|l|}{ Age } \\
\hline Sexagenarians (60-69 years) & $30(41.7 \%)$ \\
\hline Septuagenarians (70-79 years) & $42(58.3 \%)$ \\
\hline \multicolumn{2}{|l|}{ Literacy } \\
\hline Yes & $41(56.9 \%)$ \\
\hline No & $31(43.1 \%)$ \\
\hline \multicolumn{2}{|l|}{ Number of falls* } \\
\hline 1 & $32(43.8 \%)$ \\
\hline$\geq 2$ & $40(55.6 \%)$ \\
\hline \multicolumn{2}{|l|}{ Associated illnesses } \\
\hline $0-4$ & $28(38.9 \%)$ \\
\hline$\geq 5$ & $44(61.1 \%)$ \\
\hline \multicolumn{2}{|l|}{ Number of medications } \\
\hline $0-4$ & $31(43.1 \%)$ \\
\hline$\geq 5$ & $41(56.9 \%)$ \\
\hline \multicolumn{2}{|l|}{ Low vision** } \\
\hline Yes & $24(34.3 \%)$ \\
\hline No & $46(65.7 \%)$ \\
\hline \multicolumn{2}{|l|}{ Fracture due to fall* } \\
\hline Yes & $7(9.7 \%)$ \\
\hline No & $65(90.3 \%)$ \\
\hline \multicolumn{2}{|l|}{ Hospitalization due to fall* } \\
\hline Yes & $17(23.6 \%)$ \\
\hline No & $54(76.4 \%)$ \\
\hline
\end{tabular}

$*$ Values according to past year; $* *$ Missing $=2$. 
and stairs (Table 2).

When the criterion variable was physical performance, in the socio demographic and clinical variables, there was a significant difference between the WPP and BPP groups as to age group and number of associated diseases. Most of the older adults in the WPP group were Septuagenarians and had five or more associated diseases. Concerning functional independence, the WPP and BPP groups showed significant differences in most of the motor tasks of the FIM, except feeding and bowel management. Those with a poor performance were less independent in the tasks (Table 3).

In the analysis of the number of falls, in the socio demographic, clinical and physical variables, the findings showed a significant difference between the one-time fallers and the frequent fallers regarding the number of associated diseases $(p<0.001)$ and to HS $(p=0.024)$. The frequent-fallers had more associated diseases and less HS. Considering the functional variables, the frequent-fallers had a significant difference in the motor dimension of the FIM, specifically bowel management, in which they reported lower independence (Table 4).

\section{Discussion}

In the present study, the majority of fallers were Septuagenarians females with a high number of illnesses and use of medication and two or more falls. Additionally, most of them had poor physical performance, higher independence levels in ADLs and good visual acuity. These characteristics may be due to the location of the survey, as older outpatients differ from community-dwelling older adults in these factors [3,5].

These findings indicate that the present study participants had debilitating characteristics and factors often associated with the occurrence of falls; however they also showed alternative ways to overcome the functional difficulties that emerged due to age-related impairments or the consequences of falls. These data support studies conducted in outpatient or hospital settings [19].

It is important to note that, in the analysis of the factors associated to falls, it is difficult to identify which variables are causes and which are consequences of these events. Low levels of muscle strength, for example, can be a cause of falls, and the incidence of one or more falls can limit movement and, consequently, reduce the level of muscle strength. In this context, Gazzola et al. [10] and Estefani [20] reported that the fear of falling prompts relatives to take protective measures that lead the older fallers to restrict their movements to avoid the consequences of a another fall. This fact can increase the cycle of sedentary lifestyle and low physical and functional performance, causing isolation and insecurity and leading the older adult to a condition of morbidity or mortality.

Table 2. Description of physical performance of older adults according to physical and functional variables $(n=72)$

\begin{tabular}{|c|c|c|c|c|}
\hline Variables & Items & Tasks & $\mathbf{N}(\%)$ & Mean $( \pm$ SD) \\
\hline \multirow{2}{*}{ Regular physical activity } & Yes & & $19(26.4 \%)$ & \\
\hline & No & & $53(73.6 \%)$ & \\
\hline \multirow{4}{*}{ Short Physical Performance Battery (SPPB) } & Balance* & & & $2.7( \pm 1.3)$ \\
\hline & Gait* & & & $1.1( \pm 1.0)$ \\
\hline & Lower limb strength* & & & $1.1( \pm 0.8)$ \\
\hline & Total Score** & & & $5.9( \pm 2.6)$ \\
\hline Handgrip strength (0 to $50 \mathrm{~kg})$ & & & & $20.6( \pm 8.1)$ \\
\hline \multirow{13}{*}{ Functional Independence Measure ${ }^{+} * * *$} & \multirow{6}{*}{ Self-care } & 1. Eating & $56(77.8 \%)$ & \\
\hline & & 2. Grooming & $59(81.9 \%)$ & \\
\hline & & 3. Bathing/showering & $49(68.1 \%)$ & \\
\hline & & 4. Dressing upper body & $52(72.2 \%)$ & \\
\hline & & 5. Dressing lower body & $34(47.2 \%)$ & \\
\hline & & 6. Toileting & $54(75.0 \%)$ & \\
\hline & \multirow{2}{*}{ Sphincters } & 1. Bladder management & $33(45.8 \%)$ & \\
\hline & & 2. Bowel management & $48(66.7 \%)$ & \\
\hline & \multirow{5}{*}{ Mobility } & 1.Transfers: bed/chair/wheelchair & $44(61.1 \%)$ & \\
\hline & & 2. Transfers: toilet & $44(61.1 \%)$ & \\
\hline & & 3. Transfers: bathtub/shower & $43(59.7 \%)$ & \\
\hline & & 4. Locomotion: walking/wheelchair & $34(47.2 \%)$ & \\
\hline & & 5. Locomotion: stairs & $10(13.9 \%)$ & \\
\hline
\end{tabular}

$*$ Values $=0$ to 4 , varying from worst to best performance; $* *$ Values $=0$ to 12 , varying from worst to best performance; ***Values $=1$ to 7, varying from worst to best performance; $\uparrow \mathrm{N}(\%)$ of subjects with total independence $( \pm \mathrm{SD})$ in the FIM scores. 
Table 3. Comparison between older adults with best and worst physical performance according to sociodemographic, physical, clinical and functional variables $(n=72)$

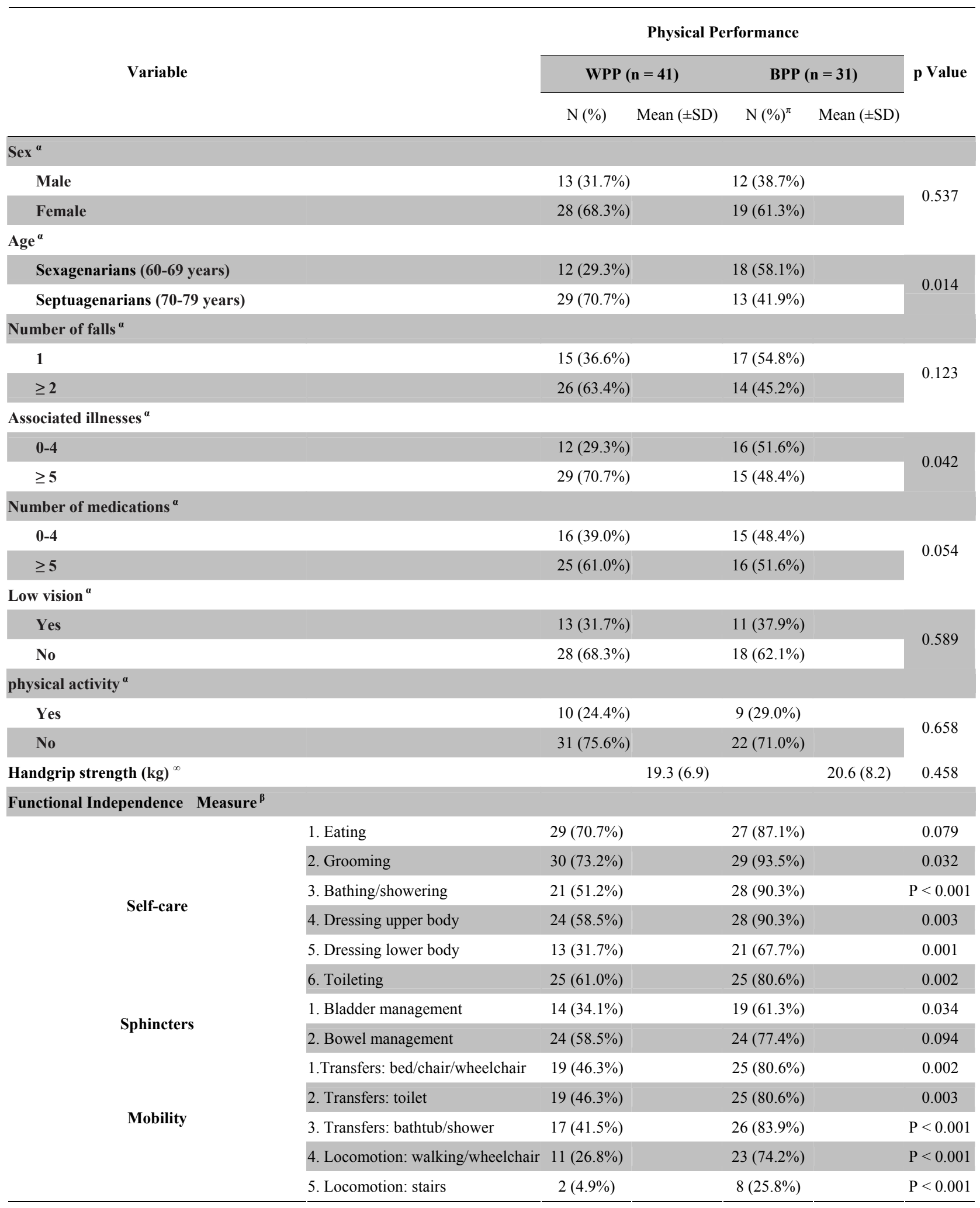

${ }^{\alpha}$ Chi-square test; $\mathrm{p}$-value $<0.05 ;{ }^{\beta}$ Mann-Whitney test; $\mathrm{p}$-value $<0.05 ;{ }^{\infty}$ Student $\mathrm{t}$ test; $\mathrm{p}$-value $<0.05 ; \mathrm{WPP}=$ worst physical performance; $\mathrm{BPP}=$ best physical performance; ${ }^{\pi} \mathrm{N}(\%)$ of subjects with total independence $( \pm \mathrm{SD})$ in the FIM scores. 
Table 4. Comparison between one-time fallers and recurrent fallers according to sociodemographic, physical, clinical and functional variables $(n=72)$

\begin{tabular}{|c|c|c|c|c|c|c|}
\hline \multirow{3}{*}{ Variable } & & \multicolumn{4}{|c|}{ Number of Fall } & \multirow{3}{*}{ p Value } \\
\hline & & \multicolumn{2}{|c|}{$1(n=32)$} & \multicolumn{2}{|c|}{$\geq 2(n=40)$} & \\
\hline & & $\mathrm{N}(\%)$ & Mean $( \pm \mathrm{SD})$ & $\mathrm{N}(\%)^{\pi}$ & Mean $( \pm \mathrm{SD})$ & \\
\hline \multicolumn{7}{|l|}{$\operatorname{Sex}^{\alpha}$} \\
\hline Male & & $14(43.7 \%)$ & & $11(27.5 \%)$ & & \multirow{2}{*}{0.150} \\
\hline Female & & $18(56.3 \%)$ & & $29(72.5 \%)$ & & \\
\hline \multicolumn{7}{|l|}{$\operatorname{Age}^{\alpha}$} \\
\hline Sexagenarians (60-69 years) & & $13(33.3 \%)$ & & $17(42.5 \%)$ & & \multirow{2}{*}{0.856} \\
\hline Septuagenarians ( $70-79$ years) & & $19(66.6 \%)$ & & $23(57.5 \%)$ & & \\
\hline \multicolumn{7}{|l|}{ Associated illnesses ${ }^{\alpha}$} \\
\hline $0-4$ & & $20(62.5 \%)$ & & $8(20.0 \%)$ & & \multirow{2}{*}{$\mathrm{P}<0.001$} \\
\hline$\geq 5$ & & $12(37.5 \%)$ & & $32(80.0 \%)$ & & \\
\hline \multicolumn{7}{|l|}{ Number of medications ${ }^{\alpha}$} \\
\hline $0-4$ & & $14(43.7 \%)$ & & $17(42.5 \%)$ & & \multirow[t]{2}{*}{0.915} \\
\hline$\geq \mathbf{5}$ & & $18(56.3 \%)$ & & $23(57.5 \%)$ & & \\
\hline \multicolumn{7}{|l|}{ Low vision ${ }^{\alpha}$} \\
\hline Yes & & $18(56.5 \%)$ & & $29(72.5 \%)$ & & \multirow{2}{*}{0.851} \\
\hline No & & $14(43.5 \%)$ & & $11(27.5 \%)$ & & \\
\hline \multicolumn{7}{|l|}{ physical activity $^{\alpha}$} \\
\hline Yes & & $8(25.0 \%)$ & & $11(27.5 \%)$ & & \multirow{2}{*}{0.811} \\
\hline No & & $24(75.0 \%)$ & & $29(72.5 \%)$ & & \\
\hline \multicolumn{7}{|l|}{ Physical Performance (SPPB) } \\
\hline & Balance & & $2.9( \pm 1.2)$ & & $2.3( \pm 1.2)$ & $0.055^{\beta}$ \\
\hline & Gait & & $1.9( \pm 1.0)$ & & $2.0( \pm 1.1)$ & $0.621^{\beta}$ \\
\hline & Lower limb strength & & $1.0( \pm 0.8)$ & & $2.3( \pm 1.2)$ & $0.845^{\beta}$ \\
\hline & Total Score & & $6.0( \pm 2.5)$ & & $5.3( \pm 2.5)$ & $0.938^{\infty}$ \\
\hline Handgrip strength $(\mathrm{kg})^{\infty}$ & & & $22.1( \pm 8.3)$ & & $18.1( \pm 6.3)$ & 0.024 \\
\hline \multicolumn{7}{|l|}{ Functional Independence Measure ${ }^{\beta}$} \\
\hline \multirow{6}{*}{ Self-care } & 1. Eating & $23(71.9 \%)$ & & $33(82.5 \%)$ & & 0.373 \\
\hline & 2. Grooming & $27(84.4 \%)$ & & $32(80 \%)$ & & 0.559 \\
\hline & 3. Bathing/showering & $25(78.1 \%)$ & & $24(60.0 \%)$ & & 0.156 \\
\hline & 4. Dressing upper body & $25(78.1 \%)$ & & $27(67.5 \%)$ & & 0.287 \\
\hline & 5. Dressing lower body & $18(56.3 \%)$ & & $16(40.0 \%)$ & & 0.172 \\
\hline & 6. Toileting & $25(78.1 \%)$ & & $29(72.5 \%)$ & & 0.647 \\
\hline \multirow{2}{*}{ Sphincters } & 1. Bladder management & $16(50.0 \%)$ & & $17(42.5 \%)$ & & 0.686 \\
\hline & 2. Bowel management & $26(8.3 \%)$ & & $22(55.0 \%)$ & & 0.014 \\
\hline \multirow{5}{*}{ Mobility } & 1.Transfers: bed/chair/wheelchair & $22(68.8 \%)$ & & $22(55.0 \%)$ & & 0.308 \\
\hline & 2. Transfers: toilet & $23(71.9 \%)$ & & $21(52.5 \%)$ & & 0.100 \\
\hline & 3. Transfers: bathtub/shower & $23(71.9 \%)$ & & $20(50.0 \%)$ & & 0.056 \\
\hline & 4. Locomotion: walking/wheelchair & $16(50.0 \%)$ & & $18(12.5 \%)$ & & 0.264 \\
\hline & 5. Locomotion: stairs & $5(15.6 \%)$ & & $5(12.5 \%)$ & & 0.932 \\
\hline
\end{tabular}

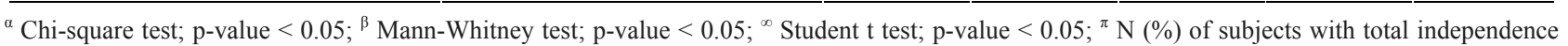
$( \pm \mathrm{SD})$ in the FIM scores. 
Physical activity is recommended as an intervention that may reduce the structural loss of physical fitness associated with aging. Most of the study participants were sedentary and had poor physical performance, which indicates that older adult fallers should be encouraged to adopt an active lifestyle to prevent falls. The WPP found in the Septuagenarians may be explained by the progressive degeneration of the physical components throughout life, together with the high number of chronic-degenerative diseases that advanced age tends to manifest. These chronic diseases, especially the musculoskeletal ones, lead to a stiffening of the joints and contribute to poor gait and balance performance [5,21-23], which can explain the relationship between physical performance and the number of diseases found in the present study.

The older adults with less HS were those who reported the occurrence of two or more falls. This measure has been regarded as a good predictor of musculoskeletal function [23-25]. The literature has also linked it to low bone mass in menopausal women, which represents a higher risk of lower limb fracture and conditions associated with frailty and falls $[8,25]$.

Regarding functional independence, the use of stairs, which depends on an ideal physical performance in gait, balance and strength, was one of the tasks associated with WPP in the present study. According to Fabricio, Rodrigues and Costa Junior [19], it is one of the most impaired activities after a fall. Still regarding functionality, the participants who reported less independence in bowel management had recurrent falls. The consequences of these events may be related to neurological diseases, such as stroke, which can reduce sphincter control and/or require the use of more medication. According to Oliveira et al. [26], the side effects of antacids (with calcium or aluminum), antispasmodics, diuretics, analgesics, anticonvulsants and antidepressants, used by older adults with severe consequences from a fall, increase the chances of impaired bowel function. These findings can also be understood in light of the bowel urgency experienced by some older adults, which leads to quick and unbalanced movements toward the bathroom and increases the risk for falls.

Older adults with less functional independence in 12 of the 14 FIM tasks had poor physical performance. Satisfactory levels of functional independence seem to generate sufficient movement to maintain physical performance; however that is insufficient to avoid falls. In a longitudinal study, Parayba and Simoes [27] verified, in the functional tasks performed by older adults, a "slight difficulty" in walking 100 meters and a decrease in the prevalence of functional disability. However, in the present research, this prevalence was distinct and related to worst physical performance, which may be explained by the debilitating characteristics of the studied group.
Although the literature shows a relationship between the occurrence of falls and low visual acuity and physical activity $[23,28-30]$, this was not observed in the two comparative analyses of the present study. These results may be explained by the limiting factors of this research, such as the low rate of active older adults, the predominance of normal or close to normal vision, the lack of details in the FIM motor tasks, as well as the indirect measures of strength, gait and balance. Environmental factors were not assessed in the present investigation, but should be considered when analyzing falls because they represent one of the major causes of these events [10,31]. In addition to the vulnerability of older adults and the consequences of diseases, environmental factors further increase the chance of falling.

This study helps increase the number studies on falls in Malaysia, especially in specific settings such as outpatient clinics, however, it is worth noting that a relevant limitation was the sample size caused by the characteristics of the group studied, which limits data extrapolation to other population groups. Given the limitations of this study, some recommendations could be made to future studies in a country that lacks studies on falls among older adults, i.e., the use of a larger sample, a longitudinal study design, a better description of the fall, the addition of tests using direct measures and the refinement of some factors frequently associated with falls.

The present research data point to the occurrence of falls and their associated characteristics as important factors to be assessed in the clinical health practice of physical therapists, physical education professionals, nurses or physicians. Fabricio, Rodrigues and Costa Junior [19] stated that a fall is indicative of undiagnosed diseases and can be a starting point for a more detailed assessment. However, the results of this and other studies show that the prevention of falls appears to be more relevant, as their consequences can be serious and, in some cases, deadly. This fact may bring about the need to shift the attention of basic health toward family support in older adult care. The reduction in the risk of falls represents a strategy to decrease the costs of older adult care and becomes possible as the predisposing factors are analyzed [8].

\section{Conclusions}

This study suggests that, among older adult fallers, the worst levels of physical performance were related to more advanced age, greater number of diseases and lower functional independence. Furthermore, recurrent falls were related to a greater number of diseases, less handgrip strength and lower functional independence in bowel management. Government incentives are also important to help in the development of educational strategies associated with prevention and exercises that improve walking and static and dynamic balance to maintain the 
movement stability and functionality of older adults. These interventions are necessary to detect the risk of falls and to recommend prevention and/or rehabilitation strategies for older adult fallers.

\section{Acknowledgements}

I like to thank Mr. S. Ganesh Pandian, coordinator and Lecturers of Physiotherapy Department, Masterskill College of Nursing and Health, Sabah, Malaysia for their Support and Co operation to initiate this Research work.

\section{REFERENCES}

[1] M. R. Perracini and L. R. Ramos, "Factors Associated with Falls in a Cohort of Elderly Community Residents," Annual Review of Public Health, Vol. 36, No. 6, 2002, pp. 709-716.

[2] M. L. Lebrao and R. Laurenti, "Health, Wellness and Aging: The SABE Study in the City of Sao Paulo," Revista Brasileira de Epidemiologia, Vol. 8, No. 2, 2005, pp. 127-141.

[3] K. A. Faulkner, M. S. Redfern, J. A. Cauley, et al., "Multitasking: Association between Poorer Performance and a History of Recurrent Falls," Journal of the American Geriatrics Society, Vol. 55, No. 44, 2007, pp. 570-576.

[4] F. V. Siqueira, L. A. Facchini, R. X. Piccini, et al., "Prevalence of Falls in the Elderly and Related Factors," Revista de Saúde Pública, Vol. 41, No. 5, 2007, pp. 749756.

[5] E. S. Nahit, A. J. Silman and G. J. Macfarlane, "The Occurrence of Falls among Patients with a New Episode of Hip Pain," Annals of the Rheumatic Diseases, Vol. 57, No. 3, 1998, pp. 166-168.

[6] T. Liu-Ambrose, K. M. Khan, J. J. Eng, P. A. Janssen, et al., "Resistance and Agility Training Reduce Fall Risk in Women Aged 75 to 85 with Low Bone Mass: A 6-Month Randomized, Controlled Trial," Journal of the American Geriatrics Society, Vol. 52, No. 5, 2004, pp. 657-665.

[7] N. van der Velde, B. H. Stricker, H. A. Pols, et al., "Risk of Falls after Withdrawal of Fall-Risk-Increasing Drugs: A Prospective Cohort Study," British Journal of Clinical Pharmacology, Vol. 63, No. 2, 2007, pp. 232-237.

[8] J. R. Rebelatto, A. P. Castro and A. Chan, "Falls in Institutionalized Elderly: General Characteristics, Determinant Factors and Relationship with Handgrip Strength," Acta Ortopédica Brasileira, Vol. 15, No. 3, 2007, pp. 151-154.

[9] Y. Rolland, V. Lauwers-cances, M. Cesari, et al., "Physical Performance Measure the Predictors of Mortality in a Cohort of Community-Dwelling Older French Women," European Journal of Epidemiology, Vol. 21, No. 2, 2006, pp. 113-122.

[10] J. M. Gazzola, M. R. Perracini, M. M. Ganança, et al., "Functional Balance Associated Factors in Elderly with Chronic Vestibular," Revista Brasileira de Otorrinolaringologia, Vol. 72, No. 5, 2006, pp. 683-690.

[11] H. Shimada, S. Obuchi, T. Furuna, et al., "New Intervention Program for Preventing Falls among Frail Elderly People," American Journal of Physical Medicine \& Re- habilitation, Vol. 83, No. 7, 2004, pp. 493-499.

[12] R. Garcia, M. D. Leme and L. E. Garcez-Leme, "Evolution of Brazilian Elderly with Hip Fracture Secondary to a Fall," Clinics (São Paulo), Vol. 61, No. 6, 2006, pp. 539544.

[13] Clinical Practice Guidelines on Management of Osteoporosis, Malaysian Osteoporosis Society, 2006.

[14] A. Braekhus, K. Laake and K. Engedal, "The Mini-Mental State Examination: Identifying the most Efficient Va- riables for Detecting Cognitive Impairment in the Elderly," Journal of the American Geriatrics Society, Vol. 40, No. 11, 1992, pp. 1139-1145.

[15] "The Prevention of Falls in Later Life, a Report of the Kellog International Work Group on the Prevention of Falls by the Elderly," Danish Medical Bulletin, Vol. 34, No. (Suppl. 4), 1987, pp. S1-24.

[16] J. M. Guralnik, E. M. Simonsick, L. Ferrucci, et al., "A Short Physical Performance Battery Assessing Lower Extremity Function: Association with Self-Reported Disability and Prediction of Mortality and Nursing Home Admission," Journals of Gerontology Medical Science, Vol. 49, No. 2, 1994, pp. M85-M94.

[17] B. B. Hamilton, C. V. Granger, F. S. Sherwin, et al., "A Uniform National Data System for Medical Rehabilitation," In: M. J. Fuhrer, Ed., Rehabilitation Outcomes: Analysis and Measurement, Brookes, Baltimore, 1987, pp. 137-147.

[18] M. G. Stineman, A. Jette, R. Fiedler, et al., "ImpairmentSpecific Dimensions within the Functional Independence Measure," Archives of Physical Medicine and Rehabilitation, Vol. 78, No. 6, 1997, pp. 636-643.

[19] S. C. C. Fabricio, R. A. P. Rodrigues and M. L. Costa Jr., "Causes and Consequences of Falls among Older Adults Seen in Public Hospital," Annual Review of Public Health, Vol. 38, No. 1, 2004, pp. 93-99.

[20] G. A. M. E. Estefani, "Profile of Elderly People Seen at a Geriatric Clinic According to the Occurrence of Falls," Dissertation, Universidade Estadual de Campinas, 2007.

[21] G. P. M. Machado, S. M. Barreto, V. M. A. Passos, et al., "Project Bamboo: Prevalence of Chronic Joint Symptoms in the Elderly," Revesta da Associação Médica Brasileira, Vol. 50, No. 4, 2004, pp. 367-372.

[22] A. Ozcan, H. Donat, N. Gelecek, et al., "The Relationship between Risk Factors for Falling and the Quality of Life in Older Adults," BMC Public Health, Vol. 5, 2005, p. 90.

[23] J. M. N. Guimaraes and P. T. V. Farinatti, "Descriptive Analysis of Variables Theoretically Associated with the Risk of Falls in Older Women," Revesta da Brasileira de Medicina do Esporte, Vol. 11, No. 5, 2005, pp. 299-305.

[24] T. Rantanen, S. Volpato, L. Ferrucci, et al., "Handgrip Strength and Cause-Specific and Total Mortality in Older Disabled Women: Exploring the Mechanism," Journal of the American Geriatrics Society, Vol. 51, No. 5, 2003, pp. 636-641.

[25] L. P. Fried, C. M. Tangen, J. Walston, et al., "Frailty in Older Adults: Evidence for a Phenotype," Journals of Gerontology Series A: Biological Sciences and Medical 
Sciences, Vol. 56, No. 3, 2001, pp. 146-156.

[26] S. C. M. Oliveira, A. M. Pinto-Neto, D. M. Conde, J. R. N. Goes, D. Santos-Sa and L. Costa-Paiva, "Fecal Incontinence in Postmenopausal Women: Prevalence, Severity and Associated Factors," Arquivos de Gastroenterologia, Vol. 43, No. 2, 2006, pp. 102-106.

[27] M. I. Parahyba and C. C. S. Simoes, "The Prevalence of Disability among the Elderly in Brazil," Ciênc Saúde Coletiva, Vol. 11, No. 4, 2006, pp. 967-974.

[28] S. R. Lord, "Visual Risk Factors for Falls in Older People," Age Ageing, Vol. 35, No. (Suppl. 2), 2006, pp. 42-45.

[29] M. Pahor, S. N. Blair, M. Espeland, et al., "Effects of a Physical Activity Intervention on Measures of Physical
Performance: Results of the Lifestyle Interventions and Independence for Elders Pilots (LIFE-P)," Journals of Gerontology Series A: Biological Sciences and Medical Sciences, Vol. 61, No. 11, 2006, pp. 1157-1165.

[30] G. Z. Mazo, D. B. Liposcki and C. Ananda, "It Provides Health Conditions, Incidence of Falls and Physical Activity Level of Older People," Revesta da Brasileira de Physiology, Vol. 11, No. 6, 2007, pp. 437-442.

[31] J. Sirola, T. Rikkonen, M. Tuppurainen, et al. "Association of Grip Strength Change with Menopausal Bone Loss and Related Fractures: A Population-Based Follow-up Study," Calcified Tissue International, Vol. 78, No. 4, 2006, pp. 218-226. 